\title{
Effect of dietary seaweed supplementation on growth performance, antioxidant and immune responses in European seabass (Dicentrarchus labrax) subjected to rearing temperature and salinity oscillations
}

\author{
Gaspar Lobo $\cdot$ Luís F. Pereira · José F. M. Gonçalves • Maria J. Peixoto • \\ Rodrigo O. A. Ozório
}

Received: 8 August 2018/Accepted: 16 October 2018/Published online: 25 October 2018

(C) The Author(s) 2018

\begin{abstract}
The current study evaluated the effects of dietary seaweed supplementation in European seabass juveniles (Dicentrarchus labrax) subjected to rearing temperature and salinity oscillations, simulating natural variations in pond aquaculture conditions. Two experimental diets where formulated: a control diet (CTRL) with no supplementation and one supplemented with 7.5\% seaweed mix (SW 2.5\% Fucus sp., 2.5\% Gracilaria sp. and $2.5 \%$ Ulva sp.). Seabass from both dietary groups (40.7 g initial body weight) was subjected to either combined salinity and temperature oscillations, or to fixed conditions. Growth performance, innate immune, and oxidative stress responses were evaluated. Results showed that seaweed supplementation had no significant effect on the analyzed parameters. However, environmental oscillations revealed significant effects on growth performance and oxidative stress response. Fish subjected to salinity and temperature oscillations had a significantly lower weight gain and daily growth index than those subjected to fixed conditions, regardless of dietary treatment. Total glutathione, oxidized glutathione, and catalase increased in fish subjected to oscillatory conditions. Lysozyme and peroxidase were not influenced by either diet or environmental conditions. In conclusion, this particular dietary seaweed mix supplementation did not mitigate the negative effects of environmental oscillations on growth performance and innate immune responses in European seabass.
\end{abstract}

Keywords Seaweeds - Dietary supplementation - Immunostimulants - European seabass - Environmental stressors $\cdot$ Immune and oxidative stress response

\section{Introduction}

In intensive aquaculture, fish are exposed to several stress factors of biological, chemical, and/or physical origin, that can affect fish well-being and immune status (Colombo et al. 1990). Sub-optimal biotic and abiotic

Electronic supplementary material The online version of this article (https://doi.org/10.1007/s40071-018-0208-3) contains supplementary material, which is available to authorized users.

G. Lobo · L. F. Pereira · J. F. M. Gonçalves · M. J. Peixoto $(\bowtie) \cdot$ R. O. A. Ozório

CIIMAR-Centro Interdisciplinar de Investigação Marinha e Ambiental, Universidade do Porto, Terminal de Cruzeiros do

Porto de Leixões, Avenida General Norton de Matos s/n, 4450-208 Matosinhos, Portugal

e-mail: mjoaodiaspeixoto@gmail.com

G. Lobo · J. F. M. Gonçalves · M. J. Peixoto

ICBAS-Instituto de Ciências Biomédicas de Abel Salazar, Universidade do Porto, Rua de Jorge Viterbo Ferreira 228,

4050-313 Porto, Portugal 
conditions are common causes for growth inhibition and mass mortalities (Sakai 1999). For instance, Vadstein et al. (1993) suggested that the majority of problems associated with fish production are caused by bacteria commonly present in hatcheries and emphasizes the importance of fish homeostasis. In addition, Björnsson and Ólafsdóttir (2006) showed a negative influence of ammonia and nitrogen high concentrations in cod rearing. It is important to highlight that fish have great adaptation strategies to counteract unfavorable environmental conditions. Hence, these constrictions will more often lead to decreases in their metabolic rates and reduction of feed intake than necessarily disease or death (Barnabe 2003).

In fish, feed intake and the kinetics of digestive processes are limited by temperature (Arana 1997). On a cellular level, temperature variations can affect protein and lipid conformation, as well as genetic modulation, altering transcription, translation, or path activation (Sengupta and Garrity 2013). Therefore, temperature influence over molecular kinetics modulates the occurrence of enzyme-subtract complexes, affecting numerous biochemical activities (Cornish-Bowden 1979). This kind of alterations induces an initial stress phase, increasing the formation of reactive oxygen species (ROS) and energy demands, potentially causing damage in proteins, lipids and DNA (Lushchak and Bagnyukova 2006). Similarly, salinity influences multiple aspects related to fish metabolism. Euryhaline fish have developed specific biochemical and physiological machinery that enables them to perceive and adapt to a wide range of salinity oscillations. When facing severe environmental conditions oscillations, compensation mechanisms are activated to relieve osmotic stress. Examples of some compensation mechanisms include alterations on fish standard metabolic rates (Lambert and Dutil 1997), feed intake, and feed conversion efficiency (Imsland et al. 2007). These adaptive strategies are a liability for aquaculture profitability, since they can cause immunosuppression, growth depression, and higher susceptibility to diseases. To solve this, alternative strategies of environmental-friendly techniques are constantly being explored. These alternatives include chemical therapy, vaccination (Bagni et al. 2000; Sakai 1999), or the application of dietary immunostimulants.

The use of dietary immunostimulants has been studied as a viable complement or alternative to traditional methods and has become widely accepted by fish farmers (Bricknell and Dalmo 2005). Immunostimulants, used as dietary supplements can improve fish immunity, increasing resistance during periods of great stress or more resilience during periods of deteriorating water conditions (Bagni et al. 2000). In vivo experiments with bacterial challenges recognized immunostimulants as antiparasitic, growth enhancers, and antibody production promoters (Bricknell and Dalmo 2005). Immunostimulatory substances, like glucans, have been reported to improve fish non-specific defense mechanisms (Jeney and Jeney 2002) and oral administration of yeast glucans increased protection against Vibrio spp. in Atlantic Salmon (Raa et al. 1992). Increased lysozyme activity was detected in seabass fed high levels of $\alpha$-tocopherol (Obach et al. 1993) and enhanced phagocytic activity was reported in seabass fed diets supplemented with levamisole and glucans (Jeney et al. 1994).

Seaweeds have been recognized as an important resource for aquaculture. They are a source of bioactive compounds, such as laminarin, fucoidan, and $\beta$-glucans that act as immunostimulants in several fish species (Mustafa and Nakagawa 1995; Peixoto et al. 2016a, b, c).

The use of dietary seaweed supplementation has revealed significant effects on growth, feed utilization, stress response, physiological condition, and carcass quality of cultured fish. Supplementation with 5\% Ulva spp. increased resistance to infection by Pasteurela piscicida in red seabream (Satoh 1987) and Ulva spp. and Chondrus crispus extracts have shown to increase respiratory burst and immune system stimulation in turbot and Atlantic salmon phagocytes (Castro et al. 2004). Besides immunocompetency, a positive correlation has been reported between seaweeds phenolic content and antioxidant capacity through lipid peroxidation inhibition (Heo et al. 2005). Extracts of red and brown seaweeds may also be effective therapeutic and prophylactic treatments against Pseudomonas spp. infection (Thanigaivel et al. 2015) and a 2.5\% dietary supplementation of Gracilaria spp. led to improved antioxidant and innate system responses in European seabass (Peixoto et al. 2016a). In addition, according to Xu and Hirata (1990), the use of Ulva sp. as a feed additive for black seabream (Acanthopagrus schlegeli) and red seabream (Pagrus major) has been shown to be beneficial on growth and color. To date, studies on the dietary Fucus sp. supplementation in fish feed are very scarce. Most recently, however, Peixoto et al. (2016a, b, c) showed that Fucus sp. supplementation of up to $7.5 \%$ in practical diets for European seabass had no impact on growth performance.

To reduce economic losses caused by immunosuppression in intensive aquaculture, it is necessary to develop strategies that account for environmental stressors for farmed fish. Therefore, the aim of this study 
was to evaluate dietary seaweed supplementation on growth performance, antioxidant, and immune responses in seabass subjected to environmental stressors.

\section{Materials and methods}

All procedures were supervised by an accredited expert in laboratory animal science by the Portuguese Veterinary Authority (1005/92, DGV-Portugal, following FELASA category C recommendations), according to the guidelines on the protection of animals used for scientific purposes from the European directive 2010/63/UE.

Experimental diets

Two experimental diets were formulated according to the species requirements (isoproteic, 48\%; isolipidic, 19\%; isoenergetic, $23 \mathrm{~kJ} \mathrm{~g}^{-1}$ ) (Table 1): a basal diet (CTRL) and a supplemented diet (SW), with an added seaweed mix at $7.5 \%$ level. The seaweed mix was supplied by ALGA+ ${ }^{\circledR}$ and contained a mixture of dried and minced Gracilaria sp., Ulva sp., and Fucus sp. at a 1:1:1 ratio. Proximal composition of seaweeds is presented in Table 2.

Table 1 Feed formulation and proximate composition of the experimental diets

\begin{tabular}{|c|c|c|}
\hline & \multicolumn{2}{|c|}{ Dietary treatments } \\
\hline & CTRL & SW \\
\hline \multicolumn{3}{|l|}{ Feed ingredients (\% DM) } \\
\hline Fishmeal standard & 10.0 & 10.0 \\
\hline Fishmeal SOLOR & 20.0 & 20.0 \\
\hline Soy protein concentrate (Soycomil) & 11.8 & 10.3 \\
\hline Wheat gluten & 4.0 & 4.0 \\
\hline Corn gluten & 8.0 & 8.0 \\
\hline Soybean meal 48 & 12.0 & 12.0 \\
\hline Rapeseed meal & 5.0 & 5.0 \\
\hline Wheat meal & 9.0 & 3.0 \\
\hline Peas gelatinized (Aquatex 8071) & 3.2 & 3.2 \\
\hline Fish oil: COPPENS & 6.5 & 6.5 \\
\hline Soybean oil & 4.0 & 4.0 \\
\hline Rapeseed oil & 4.0 & 4.0 \\
\hline Vit \& Min Premix PV01 & 1.0 & 1.0 \\
\hline Binder (Kieselghur) & 0.5 & 0.5 \\
\hline Antioxidant powder (Paramega) & 0.2 & 0.2 \\
\hline $\mathrm{MCP}$ & 0.5 & 0.5 \\
\hline L-Lysine & 0.2 & 0.2 \\
\hline DL-methionine & 0.1 & 0.1 \\
\hline Gracilaria sp. & - & 2.5 \\
\hline Ulva sp. & - & 2.5 \\
\hline Fucus sp. & - & 2.5 \\
\hline \multicolumn{3}{|l|}{ Proximate composition (\%DM) } \\
\hline Dry matter & 94.7 & 94.8 \\
\hline Ash & 8.6 & 10.6 \\
\hline Crude protein & 47.8 & 47.9 \\
\hline Crude fat & 19.1 & 19.3 \\
\hline Gross energy ( $\left.\mathrm{kJ} \mathrm{g}^{-1} \mathrm{DM}\right)$ & 22.7 & 22.4 \\
\hline
\end{tabular}


Table 2 Proximate composition (\% DM) of the seaweeds used in this trial

\begin{tabular}{lcrr}
\hline & Gracilaria spp. & Fucus spp. & Ulva spp. \\
\hline Dry matter & 93.4 & 87.0 & 85.7 \\
Crude protein & 25.9 & 17.2 & 23.2 \\
Ash & 34.3 & 20.7 & 34.8 \\
Crude fat & 1.1 & 3.4 & 1.5 \\
Gross energy $\left(\mathrm{kJ} \mathrm{g}^{-1} \mathrm{DM}\right)$ & 12.8 & 15.1 & 12.1 \\
\hline
\end{tabular}

Fish and experimental facilities

This trial was conducted in ICBAS (Instituto de Ciências Biomédicas Abel Salazar) at the Aquatic Engineering and Production Systems facilities. The experimental systems consisted of fiberglass tanks $(80 \mathrm{~L})$ connected to a single water recirculation system $\left(\mathrm{TMC}^{\circledR}\right.$ System 5000P Marine). Six tanks were used for oscillatory conditions and in parallel, and six tanks were kept under constant conditions and used as control/fixed group. Both systems (fixed and oscillatory) were identical in design. The water flow rate was set to $4 \mathrm{~L} \mathrm{~min}^{-1}$, with continuous aeration. Temperature and salinity were monitored twice a day. Oxygen, $\mathrm{pH}$, ammonia, and nitrates were monitored and kept within optimal levels. Photoperiod was set to 12:12 h light:dark and water was sterilized by ultraviolet radiation.

The values for temperature and salinity oscillations were selected from a 3-year data log period to represent the most representative combination of temperature/salinity annually observed in a Portuguese seabass farm (Materaqua Lda, Ílhavo, Portugal) (Fig. 1). Variations in temperature were achieved using thermostat heaters (Trixie $^{\circledR}-200 \mathrm{~W}$ ) and water chillers (TECO ${ }^{\circledR}$ TR60). Variations in salinity were obtained by sea salt addition or replacing salt water with dechlorinated fresh water. Groups subjected to temperature and salinity oscillations were compared with groups subjected to fixed rearing conditions (temperature $25^{\circ} \mathrm{C}$, salinity $30 \mathrm{ppt}$ ).

European seabass juveniles were provided by IPMA (Olhão, Portugal) and kept in quarantine for 2 weeks. Then, fish with an average weight of $40.7 \mathrm{~g}$ were randomly distributed into the tanks (11 fish/tank). The experimental diets, CTRL and SW, were randomly attributed to each tank, assuring three replicates in the oscillatory group and three in the fixed group for each diet. Fish were hand fed, twice a day, until apparent visual satiation and feed consumption was recorded daily.

Sampling

After 63 days, fish were anesthetized with ethylene glycol monobutyl ether $\left(0.25 \mathrm{~mL} \mathrm{~L}^{-1}\right)$, and sacrificed by decapitation. Weight was recorded for the entire lot. Blood and liver were sampled from two fish/tank. Blood was centrifuged for plasma collection and livers were immediately frozen in liquid nitrogen. All samples were then stored at $-80^{\circ} \mathrm{C}$ until further analysis.

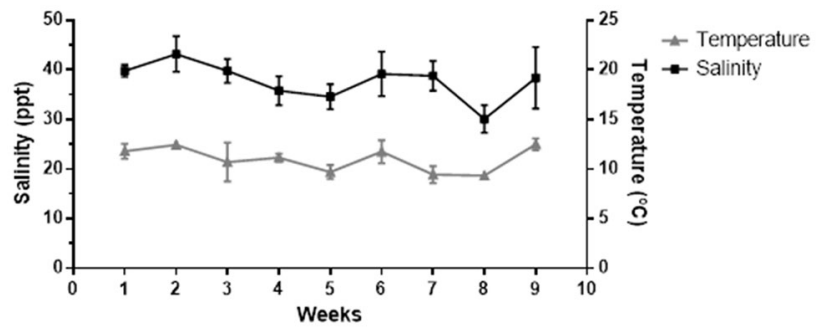

Fig. 1 Water salinity and temperature oscillations during the experimental period. Values chosen as the most representative of the natural variations in the aquaculture farm (Materaqua) over a 3-year period 
Chemical analysis

Proximate composition of the diets was determined according to AOAC (2006) methods: dry matter by ovendrying at $103{ }^{\circ} \mathrm{C}$ for $16 \mathrm{~h}$, ash by combustion in a muffle furnace (Nabertherm L9/11/B170, Bremen, Germany; $550{ }^{\circ} \mathrm{C}$ for $6 \mathrm{~h}$ ), crude protein $(\mathrm{N} \times 6.25)$ using a Leco nitrogen analyser (Model FP-528, Leco Corporation, St. Joseph, USA), lipid content by petroleum ether extraction using a Soxtherm Multistat/SX PC (Gerhardt, Königswinter, Germany; 40-60 ${ }^{\circ} \mathrm{C}$ ), and gross energy in an adiabatic bomb calorimeter (Werke C2000, IKA, Staufen, Germany).

Humoral immune parameters

Peroxidase levels were measured according to the oxidation of TMB $\left(3,3^{\prime}, 5,5^{\prime}\right.$-tetramethylbenzidine $)$ in the presence of $\mathrm{H}_{2} \mathrm{O}_{2}$ (Quade and Roth 1997). Final unit was presented as enzymatic units (EU), with one EU defined as producing an absorbance change of 1 optic density (OD). Lysozyme concentration in the plasma was determined by turbidimetric assay (Ellis 1990), measuring Micrococcus lysodeikticus lysis. Results are presented as enzymatic units, where $1 \mathrm{EU}=0.001$ absorbance units per minute.

Oxidative stress

Livers were homogenized using K-phosphate buffer $(\mathrm{pH} 7.4,0.1 \mathrm{M})$. Protein levels required for standardization of antioxidant parameters were quantified using Bradford method (Bradford 1976).

Lipid peroxidation (LPO) determination was based on malondialdehyde (MDA) level, measured as the amount of thiobarbituric acid reactive substances (TBARS) as a result of fatty acids oxidation (Ohkawa et al. 1979). Spectrophotometric readings were performed at $535 \mathrm{~nm}$.

Catalase activity (CAT) was determined by reaction with $\mathrm{H}_{2} \mathrm{O}_{2}$ (Claiborne 1985). Glutathione- $S$-transferase (GST) activity was analyzed according to Habig et al. (1974) based on the quantification of the conjugate GSH-CDNB (1-chloro-2, 4-dinitrobenzene). Glutathione peroxidase (GPx) was quantified following the method described by Mohandas et al. (1984), measuring the formation of NADP ${ }^{+}$. Glutathione reductase (GR) was determined based on NADPH oxidation measured at $340 \mathrm{~nm}$ (Cribb et al. 1989). Total and oxidized glutathione (TG and GSSG) were measured by the concomitant reaction of the GSH with 5,5'-dithiobis-(2nitrobenzoic acid) (Baker et al. 1990), read at and absorbance of $412 \mathrm{~nm}$. For GSSG evaluation, 2-vinylpyridine was used to trap the GSH present in the sample (Griffith 1980). Finally, GSH content was calculated by the difference between GSSG and TG levels.

Statistical analysis

Data were checked for normality (Shapiro/Wilk Test) and homogeneity of variances (Levene's test) and data transformation was applied when normality was not achieved. Two-way ANOVA was carried out using IBM SPSS Statistics 23. Tukey's HSD test was used for pairwise comparisons between treatments. A confidence level of $95 \%$ was considered in all statistical analysis.

\section{Results}

During the current trial, no mortalities were registered. Weight gain was significantly lower $(p<0.05)$ in fish subjected to oscillatory conditions (14.6 g and $22.6 \mathrm{~g}$ ) when compared to fish subjected to the fixed condition (33.3 $\mathrm{g}$ and $40.1 \mathrm{~g}$ ) (Table 3). The same pattern was observed for daily growth index (0.7 and 1.0 versus 1.47 and 1.6) (Table 3). Growth performance was not affected by dietary SW supplementation $(p>0.05)$ (Table 3).

Humoral immune responses (lysozyme and peroxidase activities) were not affected by dietary SW supplementation or rearing conditions $(p>0.05)$ (Fig. 2). The oxidative stress analyses showed that lipid peroxidation (LPO), glutathione peroxidase (GPx), glutathione $S$-transferase (GST), and reduced glutathione (GR) did not vary, regardless of the dietary and rearing conditions ( $p>0.05$; Figs. 3 and 4$)$. Total glutathione 
Table 3 Growth performance and feed utilization of seabass fed the experimental diets and subjected to oscillatory or fixed conditions

\begin{tabular}{|c|c|c|c|c|c|c|c|}
\hline & \multicolumn{2}{|l|}{ Oscillatory } & \multicolumn{2}{|l|}{ Fixed } & \multicolumn{3}{|c|}{$p$ value } \\
\hline & CTRL & SW & CTRL & SW & $C$ & $D$ & $C \times D$ \\
\hline Initial body weight $(\mathrm{g})$ & $26.5 \pm 2.8$ & $37.8 \pm 1.7$ & $42.9 \pm 1.6$ & $42.4 \pm 0.4$ & 0.193 & 0.546 & 0.459 \\
\hline Final body weight (g) & $43.6 \pm 1.2$ & $59.3 \pm 2.9$ & $80.2 \pm 5.7$ & $85.7 \pm 7.3$ & 0.114 & 0.310 & 0.603 \\
\hline Weight gain $(\mathrm{g})^{\mathrm{A}}$ & $14.6 \pm 4.1^{\mathrm{b}}$ & $22.6 \pm 6.1^{\mathrm{b}}$ & $33.3 \pm 12.4^{\mathrm{a}}$ & $40.1 \pm 9.5^{\mathrm{a}}$ & 0.003 & 0.342 & 0.655 \\
\hline Daily growth index ${ }^{B}$ & $0.7 \pm 0.2^{\mathrm{b}}$ & $1.0 \pm 0.2^{\mathrm{b}}$ & $1.47 \pm 0.2^{\mathrm{a}}$ & $1.6 \pm 0.1^{\mathrm{a}}$ & 0.004 & 0.489 & 0.655 \\
\hline Feed conversion ratio ${ }^{C}$ & $1.18 \pm 0.1$ & $1.73 \pm 0.04$ & $1.14 \pm 0.00$ & $1.24 \pm 0.24$ & 0.050 & 0.409 & 0.942 \\
\hline Feed intake $^{\mathrm{D}}\left(\mathrm{g} \mathrm{kg} \mathrm{ABW} \mathrm{day}^{-1}\right)$ & $118.6 \pm 4.2$ & $158.5 \pm 28.1$ & $157.5 \pm 9.9$ & $156.4 \pm 11.9$ & 0.184 & 0.342 & 0.202 \\
\hline
\end{tabular}

Corresponding $p$ values to rearing condition $(C)$ and diet $(D)$ factors, and interaction $C \times D$ are presented for each parameter. Values presented as mean \pm standard deviation. Different superscript letters indicate significant differences $(p<0.05)$

${ }^{\mathrm{A}}$ Weight gain $(\mathrm{g})=\mathrm{FBW}-\mathrm{IBW}$, where FBW and IBW are the final and initial average body weights $(\mathrm{g})$

${ }^{\mathrm{B}}$ Daily growth index $(\mathrm{DGI})=100 \times\left[(\mathrm{FBW})^{1 / 3}-(\mathrm{IBW})^{1 / 3}\right] \times$ trial duration in days

${ }^{\mathrm{C}}$ Feed conversion ratio $(\mathrm{FCR})=$ feed intake $(\mathrm{g}) /$ weight gain $(\mathrm{g})$

${ }^{\mathrm{D}} \mathrm{ABW}=(\mathrm{IBW}+\mathrm{FBW}) / 2$; day $=$ feeding trial duration

Lysozyme

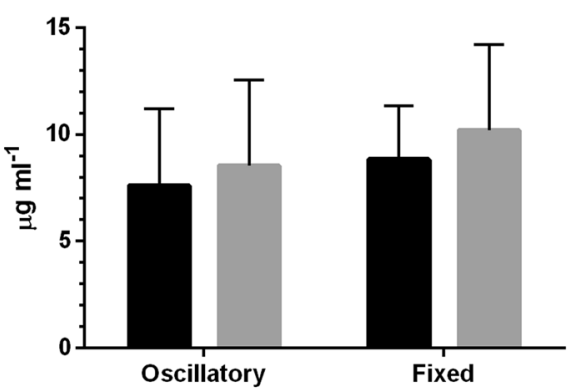

Peroxidase

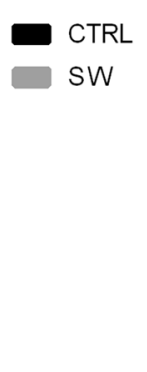

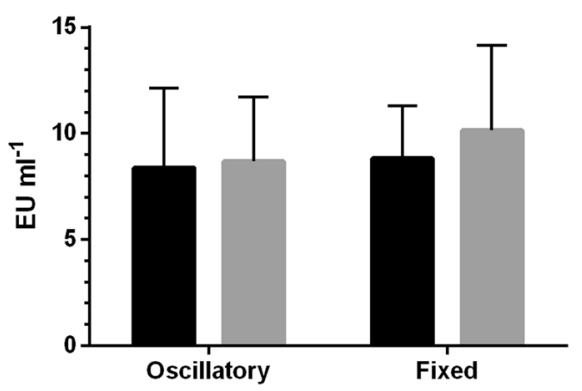

CTRL SW

Fig. 2 Lysozyme and peroxidase activities determined in seabass fed the experimental diets and subjected to oscillatory or fixed conditions. Results presented as mean \pm standard deviation

\section{Lipid peroxidation}

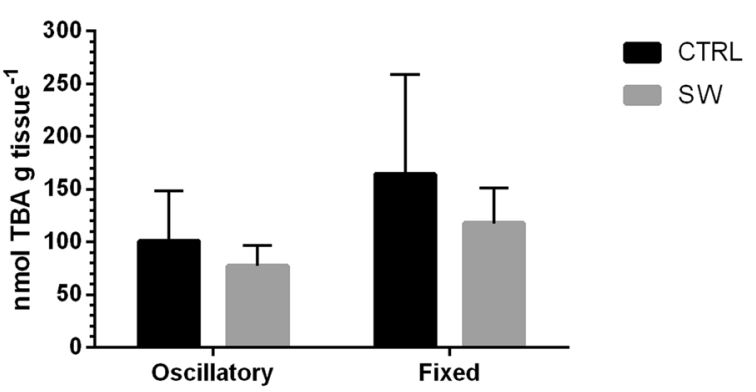

Catalase

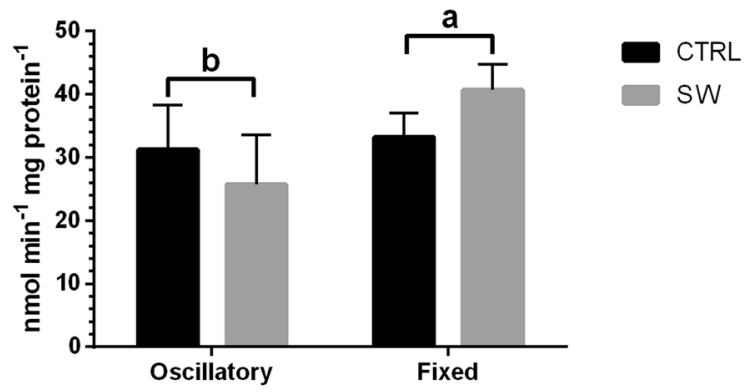

Fig. 3 Lipid peroxidation and catalase activity determined in the liver of seabass fed the experimental diets and subjected to oscillatory or fixed conditions. Results presented as mean \pm standard deviation

(TG), oxidized glutathione (GSSG), and catalase (CAT) were significantly affected by rearing conditions; temperature and salinity oscillations led to a significant increase in TG and GSSG and to a significant decrease in CAT ( $p<0.05$, Fig. 4$)$, with no influence of dietary SW supplementation $(p<0.05$; Fig. 3). 


\section{(a)}

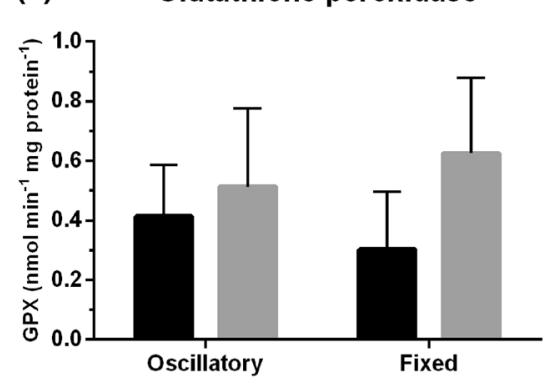

(c)

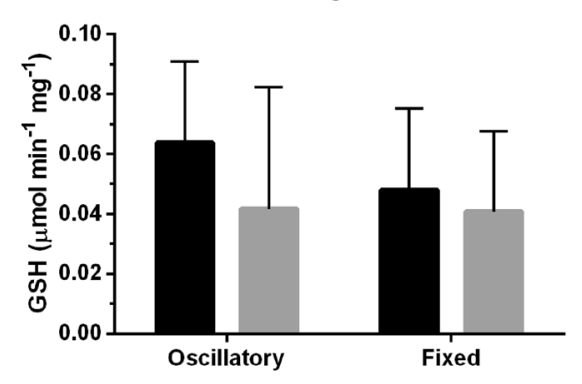

(e) Oxidized glutathione

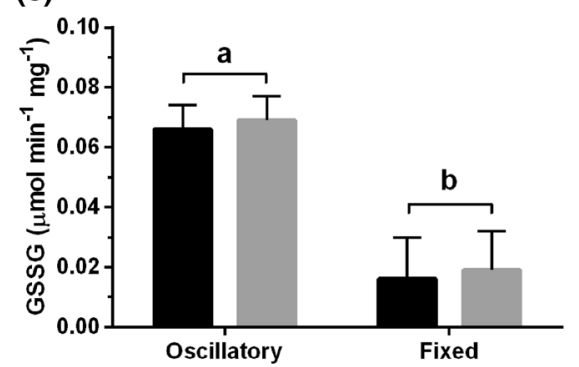

(b) Glutathione s-transferase

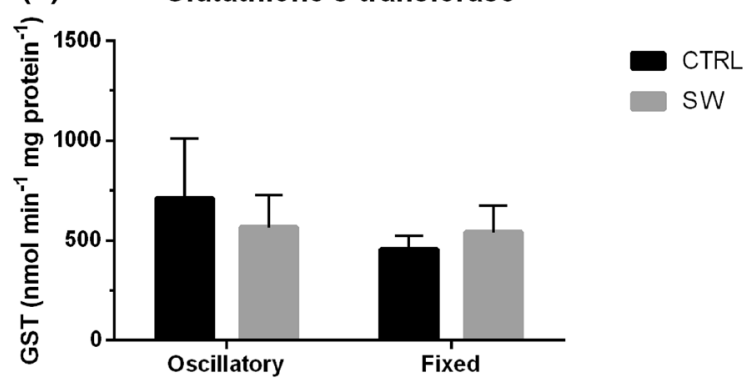

(d) Total glutathione

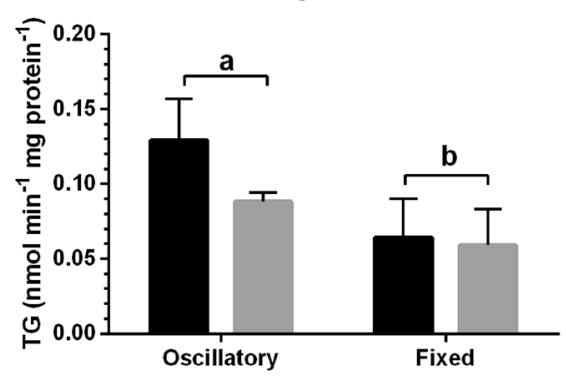

(f) GSH/GSSG ratio

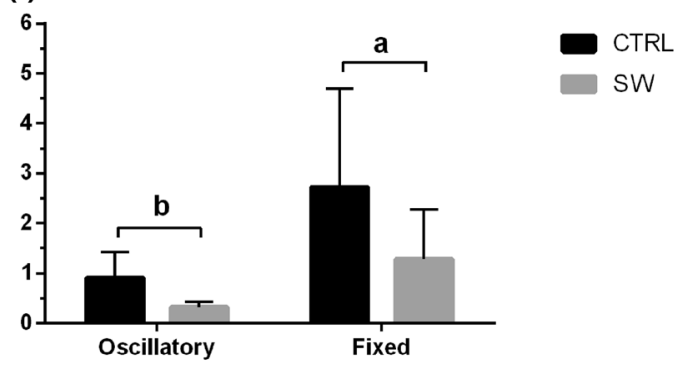

Fig. 4 Glutathione peroxidase (a), glutathione $S$-transferase (b), reduced glutathione (c), total glutathione (d) and oxidized glutathione (e) activities and GSH/GSSG ratio (f) determined in the liver of seabass fed the experimental diets and subjected to oscillatory or fixed conditions. In graphs $\mathbf{a}-\mathbf{c}$, absence of letters indicates non-significant differences and no interaction between conditions and diets. In graphs $\mathbf{d}-\mathbf{f}$, two-way ANOVA showed significant differences between conditions but not between diets, as indicated by letters

\section{Discussion}

Seaweeds have been previously studied as potential immunostimulants for many fish species including European seabass (Peixoto et al. 2016b), Nile tilapia (Güroy et al. 2007), rainbow trout (Güroy et al. 2013), and red sea bream (Mustafa and Nakagawa 1995). However, their effect as immunostimulants under environmental oscillations is yet to be accessed.

In this study, seabass growth was not influenced by dietary supplementation. This is consistent with results observed by Peixoto et al. (2016b) and Bagni et al. (2005), where no growth improvement was detected in European seabass fed diets supplemented with immunostimulants (algal extract with alginic acid and a yeast extract with $\beta$-glucans) at the same level of supplementation. Similarly, 5\% Ulva sp. showed no effects on the growth performance of Nile tilapia (Güroy et al. 2007), while in European seabass, $10 \%$ inclusion of $U$. rigida or Gracilaria bursa-pastoris did not compromise growth (Valente et al. 2006). In addition, for striped mullet (Wassef et al. 2001) and Nile tilapia (Azaza et al. 2008), 10-25\% inclusion with Ulva sp. had no effects on the 
growth performance of these species. On the other hand, Mustafa and Nakagawa (1995) showed that 5\% inclusion of a seaweed mix (Ascophyllum nodosum, Porphyra yezeoensis, and U. pertusa) increased body weight and feed utilization of red seabream fingerlings.

Temperature and salinity combined effect has been reported as the main parameter affecting seabass growth (Conides and Glamuzina 2006). In this study, dietary seaweed supplementation had no effect on seabass growth performance, while the oscillatory environmental factors were the most accountable for the reduced growth performance. Both temperature and salinity played an important role in the outcome of the current study. Nevertheless, low temperatures possibly played a stronger role, as it is one of the most important environmental factor affecting the biochemical and physiological processes of aquatic organisms (Reynolds and Casterlin, 1979). Fish subjected to oscillatory conditions showed a lower growth performance in terms of daily growth index and weight gain when compared to those reared at fixed conditions. This is in agreement with Bagni et al. (2005) that associated growth suppression in seabass fed a combination of yeast $\beta$-glucan and alginic acid to sub-optimal water temperature.

The compounds associated with the immunostimulant properties of seaweeds still require more clarification. Nonetheless, polysaccharides, such as those present in seaweeds, have been linked to enhancements of fish innate immune system (Kim et al. 2012). Lysozyme and peroxidase are key components of fish innate immunity, acting against pathogens by disrupting their cell walls, either directly or through oxidative radicals action (Nayak 2010). In another study, the inclusion G. lemaneiformis showed to increased lysozyme activity in white-spotted spinefoot, associating it with the polysaccharides, vitamin $\mathrm{C}$, and $\beta$-carotenes present in seaweeds (Xu et al. 2011). However, in the present trial, lysozyme and peroxidase activities of seabass were not affected by dietary seaweed supplementation nor by the environmental conditions. Similarly, previous studies report no effects in lysozyme and peroxidase activities for Nile tilapia fed diets supplemented with 5\% and 10\% Ulva spp. (Valente et al. 2006) and in European seabass fed diets with algal extract (Lauridsen and Buchmann 2010). On the other hand, an increase in lysozyme concentration was reported in European seabass when fed a seaweed supplemented diet (Peixoto et al. 2016c) and when fed a combination of dietary glucans and vitamins (Bagni et al. 2000), contradicting present results. Given this, we hypothesize that the beneficial effects of seaweeds on the innate immune response may be highly influenced by biotic and abiotic factors such as species, age, weight, rearing water conditions, and/or seaweed composition.

Environmental factors such as rearing temperature and salinity have been described to influence cellular antioxidant balance. Vinagre et al. (2012) showed that both LPO and CAT increased when European seabass was reared at temperatures outside the optimal range $\left(24{ }^{\circ} \mathrm{C}\right)$. Similar results were presented by Madeira et al. (2013), where multiple estuarine fish species (including seabass) were collected and subjected to a temperature increase of $1{ }^{\circ} \mathrm{C} / \mathrm{h}$, starting at $24^{\circ} \mathrm{C}$. In this study, LPO, CAT, and GST simultaneously increased with temperature rise. In our work, no differences were found in these parameters. It is possible that temperature oscillation masks consistent reactions from these parameters. However, GSSG in this work was significantly higher in the oscillatory treatments. Eroglu et al. (2015) showed that fish exposed to heavy metals had reduced GSH/GSSG levels, due to the consumption of GSH and formation of GSSG. Leggatt et al. (2007) showed that besides metal toxicity, temperature alone could influence GSH levels, with fish being acclimatized within the range of comfort temperatures showed increased GSH transcription. Altogether, GSH appears to reduce in hazardous conditions, either by conception (promoting GSSG increase) or/and by reducing its formation.

Results from present study indicate that dietary seaweed supplementation had no influence on these oxidative stress biomarkers, which has also been observed by Peixoto et al. (2016b). However, the differences observed are tightly associated with temperature and salinity oscillations which is well described by several works (Loro et al. 2012; Madeira et al. 2013; Vinagre et al. 2012). In this work, TG levels were higher in fish subjected to the oscillatory condition. Similarly, Eroglu et al. (2015) observed an increase of oxidized glutathione (GSSG) leading to higher TG concentrations and lower GSH/GSSG ratio. Therefore, it appears plausible to consider that the oscillatory environmental conditions acted as ROS inducing event. TG levels behave as a potential antioxidant reserve that reduces in prolonged exposure to stress (Eroglu et al. 2015). In more detail, TG levels seem to oscillate as compensatory effect of GSH depletion, due to antioxidant activities (Guyonnet et al. 1999; Tan et al. 1998). According to Vinagre et al. (2012), CAT activities in juvenile seabass are highly sensitive to environmental temperature, particularly those outside the optimal range of the species, which is in accordance with our results. 
This work showed that seaweed supplementation in European Seabass juveniles does not mitigate the effects of environmental oscillations. Therefore, dietary supplementation trials should focus on determining the bioactive compounds present in seaweeds and their association with specific responses. In addition, antioxidant responses in this work were altered solely in the glutathione's system suggesting a similarity to antioxidant responses in toxicity trials. However, antioxidant results were affected by the high deviation between trials suggesting a greater number of samples should be considered for these parameters.

Overall the differences observed in our study were mainly associated with the oscillating conditions and not the dietary seaweed supplementation, nor were interactions between factors detected for the analyzed parameters.

Acknowledgements The current study was supported by the Research Line INSEAFOOD of the project INNOVMAR-Innovation and Sustainability in the Management and Exploitation of Marine Resources (reference NORTE-01-0145-FEDER000035), funded by the Northern Regional Operational Programme (NORTE 2020) through the ERDF.

Open Access This article is distributed under the terms of the Creative Commons Attribution 4.0 International License (http:// creativecommons.org/licenses/by/4.0/), which permits unrestricted use, distribution, and reproduction in any medium, provided you give appropriate credit to the original author(s) and the source, provide a link to the Creative Commons license, and indicate if changes were made.

\section{References}

Arana LV (1997) Princípios químicos de qualidade da água em aquicultura: uma revisáo para peixes e camaróes. UFSC, Florianopolis

Azaza MS, Mensi F, Ksouri J, Dhraief MN, Brini B, Abdelmouleh A, Kraïem MM (2008) Growth of Nile tilapia (Oreochromis niloticus L.) fed with diets containing graded levels of green algae ulva meal (Ulva rigida) reared in geothermal waters of southern Tunisia. J Appl Ichthyol 24:202-207. https://doi.org/10.1111/j.1439-0426.2007.01017.x

Bagni M, Archetti L, Amadori M, Marino G (2000) Effect of long-term oral administration of an immunostimulant diet on innate immunity in sea bass (Dicentrarchus labrax). J Vet Med Res 47:745-751. https://doi.org/10.1111/j.1439-0450.2000.00412.x

Bagni M et al (2005) Short-and long-term effects of a dietary yeast $\beta$-glucan (Macrogard) and alginic acid (Ergosan) preparation on immune response in sea bass (Dicentrarchus labrax). Fish Shellfish Immunol 18:311-325. https://doi.org/10.1016/j.fsi. 2004.08.003

Baker MA, Cerniglia GJ, Zaman A (1990) Microtiter plate assay for the measurement of glutathione and glutathione disulfide in large numbers of biological samples. Anal Biochem 190:360-365. https://doi.org/10.1016/0003-2697(90)90208-Q

Barnabe G (2003) Aquaculture: biology and ecology of cultured species. Ellis Horwood series in aquaculture and fisheries support. CRC Press, Boca Raton

Björnsson B, Ólafsdóttir SR (2006) Effects of water quality and stocking density on growth performance of juvenile cod (Gadus morhua L.). ICES J Mar Sci 63:326-334. https://doi.org/10.1016/j.icesjms.2005.10.010

Bradford MM (1976) A rapid and sensitive method for the quantitation of microgram quantities of protein utilizing the principle of protein-dye binding. Anal Biochem 72:248-254. https://doi.org/10.1016/0003-2697(76)90527-3

Bricknell I, Dalmo RA (2005) The use of immunostimulants in fish larval aquaculture. Fish Shellfish Immunol 19:457-472. https://doi.org/10.1016/j.fsi.2005.03.008

Castro R, Zarra I, Lamas J (2004) Water-soluble seaweed extracts modulate the respiratory burst activity of turbot phagocytes. Aquaculture 229:67-78. https://doi.org/10.1016/S0044-8486(03)00401-0

Claiborne A (1985) Catalase activity. In: Greenwald RA (ed) CRC handbook of methods for oxygen radical research. CRC Press, Boca Raton, pp 283-284

Colombo L, Belvedere P, Pickering A, Schreck C (1990) Stress inducing factors and stress reaction in aquaculture. European Aquaculture Society Special Publication, Belgium

Conides AJ, Glamuzina B (2006) Laboratory simulation of the effects of environmental salinity on acclimation, feeding and growth of wild-caught juveniles of European sea bass Dicentrarchus labrax and gilthead sea bream, Sparus aurata. Aquaculture 256:235-245. https://doi.org/10.1016/j.aquaculture.2006.02.029

Cornish-Bowden A (1979) Chapter 8-Control of enzyme activity. In: Cornish-Bowden A (ed) Fundamentals of enzyme kinetics. Butterworth-Heinemann, pp 147-176. https://doi.org/10.1016/B978-0-408-10617-7.50013-4

Cribb AE, Leeder JS, Spielberg SP (1989) Use of a microplate reader in an assay of glutathione reductase using 5,5'-dithiobis (2nitrobenzoic acid). Anal Biochem 183:195-196. https://doi.org/10.1016/0003-2697(89)90188-7

Ellis AE (1990) Lysozyme assays. In: Stolen JS, Fletcher TC, Anderson DP, Roberson BS, Van Muiswinkel WB (eds) Techniques in fish immunology. SOS Publications, Fair Haven, pp 101-103

Eroglu A, Dogan Z, Kanak E, Atli G, Canli M (2015) Effects of heavy metals (Cd, Cu, Cr, Pb, Zn) on fish glutathione metabolism. Environ Sci Pollut Res Int 22:3229-3237. https://doi.org/10.1007/s11356-014-2972-y

Griffith W (1980) Determination of glutathione and glutathione disulfide using glutathione reductase and 2-vinylpyridine. Anal Biochem 106:207-212. https://doi.org/10.1016/0003-2697(80)90139-6 
Güroy BK, Cirik Ş, Güroy D, Sanver F, Tekinay AA (2007) Effects of Ulva rigida and Cystoseira barbata meals as a feed additive on growth performance, feed utilization, and body composition of Nile tilapia, Oreochromis niloticus. Turk J Vet Anim Sci 31:91-97

Güroy B, Ergün S, Merrifield DL, Güroy D (2013) Effect of autoclaved Ulva meal on growth performance, nutrient utilization and fatty acid profile of rainbow trout, Oncorhynchus mykiss. Aquacult Int 21:605-615. https://doi.org/10.1007/s10499-0129592-7

Guyonnet D, Siess M-H, Le Bon A-M, Suschetet M (1999) Modulation of phase II enzymes by organosulfur compounds from allium vegetables in rat tissues. Toxicol Appl Pharmacol 154:50-58. https://doi.org/10.1006/taap.1998.8574

Habig WH, Pabst MJ, Jakoby WB (1974) Glutathione $S$-transferases: the first enzymatic step in mercapturic acid formation. J Biol Chem 249:7130-7139

Heo S-J, Park E-J, Lee K-W, Jeon Y-J (2005) Antioxidant activities of enzymatic extracts from brown seaweeds. Bioresour Technol 96:1613-1623. https://doi.org/10.1016/j.biortech.2004.07.013

Imsland AK, Björnsson BT, Gunnarsson S, Foss A, Stefansson SO (2007) Temperature and salinity effects on plasma insulin-like growth factor-I concentrations and growth in juvenile turbot (Scophthalmus maximus). Aquaculture 271:546-552. https://doi. org/10.1016/j.aquaculture.2007.07.007

Jeney G, Jeney Z (2002) Application of immunostimulants for modulation of the non-specific defense mechanisms in sturgeon hybrid: Acipenser ruthenu $\times$ A. baerii. J Appl Ichthyol 18:416-419. https://doi.org/10.1046/j.1439-0426.2002.00405.x

Jeney G, Galeotti M, Volpatti D (1994) Effect of immunostimulation on the non-specific immune response of sea bass Dicentrarchus labrax. In: International symposium on aquatic animal health, Seattle, Washington, USA, 4e8 September

Kim J-H, Lee J-S, Kang J-C (2012) Effect of inorganic mercury on hematological and antioxidant parameters on olive flounder Paralichthys olivaceus. Fish Aquat Sci 15:215-220. https://doi.org/10.5657/FAS.2012.0215

Lambert Y, Dutil J-D (1997) Can simple condition indices be used to monitor and quantify seasonal changes in the energy reserves of cod (Gadus morhua)? Can J Fish Aquat Sci 54:104-112. https://doi.org/10.1139/f96-149

Lauridsen JH, Buchmann K (2010) Effects of short-and long-term glucan feeding of rainbow trout (Salmonidae) on the susceptibility to Ichthyophthirius multifiliis infections. Acta Ichthyol Piscat 40:61-66. https://doi.org/10.3750/AIP2010.40.1. 08

Leggatt R, Brauner C, Schulte P, Iwama G (2007) Effects of acclimation and incubation temperature on the glutathione antioxidant system in killifish and RTH-149 cells. Comp Biochem Physiol A Mol Integr Physiol 146:317-326

Loro V, Jorge M, Silva K, Wood C (2012) Oxidative stress parameters and antioxidant response to sublethal waterborne zinc in a euryhaline teleost Fundulus heteroclitus: protective effects of salinity. Aquat Toxicol 110:187-193. https://doi.org/10.1016/j. aquatox.2012.01.012

Lushchak VI, Bagnyukova TV (2006) Effects of different environmental oxygen levels on free radical processes in fish. Comp Biochem Physiol B Biochem Mol Biol 144:283-289. https://doi.org/10.1016/j.cbpb.2006.02.014

Madeira D, Narciso L, Cabral HN, Vinagre C, Diniz MS (2013) Influence of temperature in thermal and oxidative stress responses in estuarine fish. Comp Biochem Physiol A Mol Integr Physiol 166:237-243. https://doi.org/10.1016/j.cbpa.2013.06.008

Mohandas J, Marshall JJ, Duggin GG, Horvath JS, Tiller DJ (1984) Differential distribution of glutathione and glutathione-related enzymes in rabbit kidney: possible implications in analgesic nephropathy. Biochem Pharmacol 33:1801-1807. https://doi. org/10.1016/0006-2952(84)90353-8

Mustafa MG, Nakagawa H (1995) A review: dietary benefits of algae as an additive in fish feed. Isr J Aquacult (Bamid) 47:155-162. https://doi.org/10.1371/journal.pone.0124042

Nayak S (2010) Probiotics and immunity: a fish perspective. Fish Shellfish Immunol 29:2-14. https://doi.org/10.1016/j.fsi.2010. 02.017

Obach A, Quentel C, Laurencin FB (1993) Effects of alpha-tocopherol and dietary oxidized fish oil on the immune response of sea bass Dicentrarchus labrax. Dis Aquat Organ 15:175-185. https://doi.org/10.3354/dao015175

Ohkawa H, Ohishi N, Yagi K (1979) Assay for lipid peroxides in animal tissues by thiobarbituric acid reaction. Anal Biochem 95:351-358. https://doi.org/10.1016/0003-2697(79)90738-3

Peixoto et al (2016a) Effects of dietary Gracilaria sp. and Alaria sp. supplementation on growth performance, metabolic rates and health in meagre (Argyrosomus regius) subjected to pathogen infection. J Appl Phycol 29:433-447. https://doi.org/10.1007/ s10811-016-0917-1

Peixoto et al (2016b) Role of dietary seaweed supplementation on growth performance, digestive capacity and immune and stress responsiveness in European seabass (Dicentrarchus labrax). Aquacult Rep 3:189-197. https://doi.org/10.1016/j.aqrep.2016. 03.005

Peixoto MJ et al (2016c) Diets supplemented with seaweed affect metabolic rate, innate immune, and antioxidant responses, but not individual growth rate in European seabass (Dicentrarchus labrax). J Appl Phycol 28:2061-2071. https://doi.org/10. 1007/s10811-015-0736-9

Quade MJ, Roth JA (1997) A rapid, direct assay to measure degranulation of bovine neutrophil primary granules. Vet Immunol Immunopathol 58:239-248. https://doi.org/10.1016/S0165-2427(97)00048-2

Raa J, Rørstad G, Engstad R, Robertsen B (1992) The use of immunostimulants to increase resistance of aquatic organism to microbial infections. In: Sharif MI, Subasinghe RP, Arthur JR (eds) Diseases in Asian aquaculture. Fish health section. Asian Fisheries Society, Manila, pp 39-50

Reynolds WW, Casterlin ME (1979) Behavioral thermoregulation and the "final preferendum" paradigm. Am Zool 19(1):211-224

Sakai M (1999) Current research status of fish immunostimulants. Aquaculture 172:63-92. https://doi.org/10.1016/S00448486(98)00436-0

Satoh K (1987) Effect of Ulva meal supplementation on disease resistance of red sea bream. Nippon Suisan Nippon Suisan Gakk 53:1115-1120. https://doi.org/10.2331/suisan.53.1115 
Sengupta P, Garrity P (2013) Sensing temperature. Curr Biol 23:304-307. https://doi.org/10.1016/j.cub.2013.03.009

Tan S, Sagara Y, Liu Y, Maher P, Schubert D (1998) The regulation of reactive oxygen species production during programmed cell death. J Cell Biol 141:1423-1432. https://doi.org/10.1083/jcb.141.6.1423

Thanigaivel S, Chandrasekaran N, Mukherjee A, Thomas J (2015) Investigation of seaweed extracts as a source of treatment against bacterial fish pathogen. Aquaculture 448:82-86. https://doi.org/10.1016/j.aquaculture.2015.05.039

Vadstein O, Øie G, Olsen Y, Salvesen I, Skjermo J, Skjåk-Bræk G (1993) A strategy to obtain microbial control during larval development of marine fish. Paper presented at the fish farming technology: proceedings of the first international conference of on fish farming technology, Rotterdam

Valente LMP, Gouveia A, Rema P, Matos J, Gomes EF, Pinto IS (2006) Evaluation of three seaweeds Gracilaria bursa-pastoris, Ulva rigida and Gracilaria cornea as dietary ingredients in European sea bass (Dicentrarchus labrax) juveniles. Aquaculture 252:85-91. https://doi.org/10.1016/j.aquaculture.2005.11.052

Vinagre C, Madeira D, Narciso L, Cabral HN, Diniz M (2012) Effect of temperature on oxidative stress in fish: lipid peroxidation and catalase activity in the muscle of juvenile seabass, Dicentrarchus labrax. Ecol Indic 23:274-279. https://doi.org/10.1016/ j.ecolind.2012.04.009

Wassef E, El Masry M, Mikhail F (2001) Growth enhancement and muscle structure of striped mullet, Mugil cephalus L., fingerlings by feeding algal meal-based diets. Aquacult Res 32:315-322. https://doi.org/10.1046/j.1355-557x.2001.00043.x

Xu B, Hirata H (1990) Effects of feed additive Ulva reproduced in feedback culture system on the growth and color of red sea bream, Pagrus major. Aquacult Sci 38(2):177-182. https://doi.org/10.11233/aquaculturesci1953.38.177

Xu S, Zhang L, Wu Q, Liu X, Wang S, You C, Li Y (2011) Evaluation of dried seaweed Gracilaria lemaneiformis as an ingredient in diets for teleost fish Siganus canaliculatus. Aquacult Int 19:1007-1018. https://doi.org/10.1007/s10499-011$9418-\mathrm{z}$

\section{Publisher's Note}

Springer Nature remains neutral with regard to jurisdictional claims in published maps and institutional affiliations. 